$40(1) \mid 2011$

Varia

Bogotá, 4-9 de abril de 2011

\title{
América Latina y el mundo ante la guerra civil española
}

Bogotá, 4-9 de abril de 2011

\section{Bernard Lavallé}

\section{OpenEdition}

\section{Journals}

Edición electrónica

URL: http://journals.openedition.org/bifea/1700

DOI: 10.4000/bifea. 1700

ISSN: 2076-5827

\section{Editor}

Institut Français d'Études Andines

\section{Edición impresa}

Fecha de publicación: 1 abril 2011

Paginación: 228-231

ISSN: 0303-7495

\section{Referencia electrónica}

Bernard Lavallé, «América Latina y el mundo ante la querra civil española », Bulletin de l'Institut français d'études andines [En línea], 40 (1) | 2011, Publicado el 01 octubre 2011, consultado el 07 noviembre 2020. URL : http://journals.openedition.org/bifea/1700 ; DOI : https://doi.org/10.4000/bifea.1700

\section{(c) (i) $\ominus$}

Les contenus du Bulletin de l'Institut français d'études andines sont mis à disposition selon les termes de la licence Creative Commons Attribution - Pas d'Utilisation Commerciale - Pas de Modification 4.0 International. 


\section{AMÉRICA LATINA Y EL MUNDO ANTE LA GUERRA CIVIL ESPAÑOLA}

\section{Bogotá, 4-9 de abril de 2011}

Este es el título del simposio que el profesor Heraclio Bonilla organizó entre el 4 y el 9 de abril de 2011 en Bogotá con la Embajada de España en Colombia, el Grupo de Investigación en Historia Económica y Social y el IFEA (UMIFRE 17, CNRS-MAEE), con la ayuda y bajo los auspicios de la Universidad Nacional de Colombia, de la Embajada de Francia, de Colsanitas, del Instituto Italiano di Cultura y del Instituto Colombiano de Antropología e Historia.

El motivo era conmemorar el 80 aniversario de la proclamación de la república en Madrid (14 de abril de 1931), pero el objetivo científico era también analizar, además de los aspectos esenciales del conflicto, las repercusiones que éste tuvo en el continente americano. 


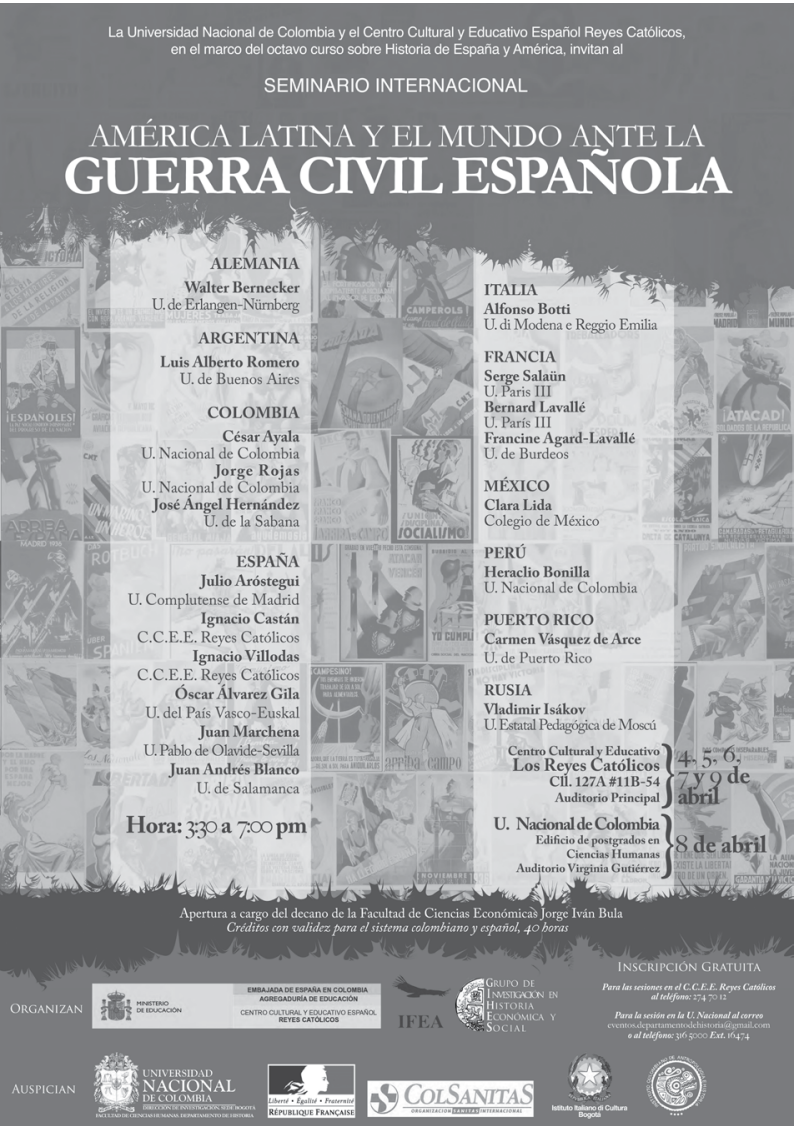
el contexto español del conflicto, son de destacar las de Ignacio Castán (CNT y FAl, el exilio de fuera y el exilio de dentro) centrada sobre las vivencias de los anarquistas durante el conflicto y después de él, la cuestión de la construcción de la memoria combatiente y resistente ya durante la batalla de Madrid (Juan Marchena Fernández, La memoria obstinada. Sobre libros heridos y osos polares. Los desastres de la guerra en la visión de los poetas latinoamericanos en España, 1936-1939) y un problema poco estudiado, por no decir olvidado, el de la preservación de las obras de arte durante el conflicto (en particular en Madrid largamente asediado y bombardeado), y el dilema de mandarlas fuera del país para ponerlas a salvo de posibles destrucciones con el riesgo de que se extraviaran, o fueran robadas en el extranjero (Ignacio Villodas, Patrimonio histórico-artístico y Guerra Civil: Museo del Prado).

El segundo conjunto de estudios del simposio concernía a las repercusiones de la Guerra Civil en los países europeos. Dos ponencias prácticamente paralelas trataban de los casos alemán e italiano (Walter Bernecker, Alemania y la Guerra Civil española y Alfonso Botti, Guerra Civil y régimen fascista en Europa). Ese paralelismo se debía al hecho de que los gobiernos de ambos países entonces fascistas ayudaron, como 
se sabe de manera decisiva, al bando franquista, con armamento, tropas y dinero mientras que, por el lado republicano, las filas interbrigadistas contaron con no pocos italianos y alemanes para los que combatir al fascismo en España era luchar por el regreso de la democracia en su propia patria.

De alguna manera, en el conflicto tanto Italia como Alemania tuvieron entonces cada una dos historias, por supuesto encontradas, reflejos de la situación en muchos aspectos trágica por la que estaban atravesando, pero también reveladoras de la pugna a nivel internacional que empezaba a enfrentar a una Europa contra otra, preámbulo de la conflagración que se desataría en el continente pocos meses después de terminar la Guerra Civil.

Dos ponencias analizaron el caso francés. Una (Serge Salaün, Francia ante la Guerra de España: solidaria e insolidaria) se centró en el problema de la no intervención que Inglaterra consiguió imponer a la Francia socialista del Front Populaire. Léon Blum no pudo sino aceptar esa posición, pero en secreto trató en lo posible de ayudar a los republicanos y lo consiguió, en contra de lo que a menudo se ha afirmado. S. Salaün explicó además la complejidad de la posición francesa haciendo hincapié no solo en planteamientos políticos sino también en el desarrollo, en la Francia de los años 30 del siglo pasado, de las ideas pacifistas, consecuencia del trauma generacional causado en el país por la primera guerra mundial.

Por su parte, Francine Agard-Lavallé y Bernard Lavallé trataron del primer exilio español, tomando un ejemplo concreto (La emigración española en Francia a raíz de la Guerra Civil española: el caso de Burdeos). Demostraron que ese exilio fue mucho más diverso de lo que se suele pensar, que no se puede reducir a las consecuencias de la Retirada de comienzos del año 1939 en Cataluña, ya que concernió también a lo que pasó en Asturias (en 1934) y en el País Vasco (en 1936 y 1937). Insistieron también sobre las múltiples manifestaciones de solidaridad que entonces surgieron en la población francesa, sin ocultar las dificultades que aparecieron por tres motivos: las ambigüedades del gobierno francés, las diferencias de actitudes entre gente de izquierda y de derecha $y$, finalmente, las consecuencias de la guerra franco-alemana que, a partir de setiembre de 1939, suscitó un enorme movimiento de desplazados que hizo que se olvidara a los españoles recién llegados.

Por su parte, Vladimir Isákov, trató de Anarquistas y comunistas en la guerra civil española, una visión desde los archivos soviéticos. Enfocó esa interesante cuestión a partir de los documentos emitidos por un cónsul soviético en Barcelona.

El tercer conjunto de ponencias estaba centrado en las consecuencias de la Guerra Civil en diversos países de América. Esas fueron muy diversas. Óscar Álvarez Gila presentó la actuación del gobierno vasco en los Estados Unidos («We are catholics no reds» La Guerra Civil española y la Iglesia católica norteamericana a través de la propaganda del Gobierno vasco), Carmen Vásquez de Arce se centró sobre Puerto Rico, escogiendo como ejemplo emblemático de un escultor (La repercusión de la Guerra Civil española en Puerto Rico. El caso de Compostela).

Tomando en cuenta las situaciones nacionales, se pudo notar cómo la llegada de los emigrados españoles a partir de 1939 y también las discusiones acaloradas 
que la Guerra Civil suscitó en todas las prensas y en todos los ámbitos políticos de Latinoamérica, constituyeron finalmente un elemento nada desdeñable, $y$ a veces decisivo, en los grandes debates nacionales que entonces conocían las repúblicas del continente.

Eso se dio por supuesto según modalidades variadas, con consecuencias y proyecciones nacionales también diferentes, pero esas ponencias fueron todas al respecto muy esclarecedoras y documentadas. Juan Andrés Blanco, insistió sobre el papel de la importante y pudiente comunidad española en la Isla (El conflicto de la «dos Españas» en Cuba). Clara Lida pormenorizó el aporte de la emigración hispana en México y el papel del presidente Cárdenas (México ante la guerra Civil y el exilio: la solidaridad del cardenismo). Luis Alberto Romero inscribió de manera muy sugerente los debates argentinos en torno a la Guerra Civil en las pugnas que, por esas mismas fechas, había a propósito de la democracia a orillas del Plata (La Guerra Civil española y la polarización ideológica y política argentina, 1936-1946). José Ángel Hernández (La colonia española en Colombia) y César Ayala Diego (La historia como parodia: imaginarios conservadores colombianos frente a la Guerra Civil española) hicieron lo mismo para Colombia, demostrando, en particular el último, cómo el ejemplo franquista dejó una impronta muy profunda en el viraje de la derecha colombiana a finales de los años 1930.

En fin, es de destacar la intervención de Heraclio Bonilla que puso en relación las evoluciones de la sociedad peruana desde finales del siglo XIX con la toma de posición de Vallejo entonces radicado en París frente al conflicto español (Perú y España en la poesía de César Vallejo).

Como se ve, muchos han sido los aportes de este encuentro, en particular en la medida en que, tanto en el caso de Europa como de América, se demostraron las repercusiones del conflicto fuera de los límites de la Península y en los debates internos de no pocos países que de una u otra manera tuvieron que ver con él. 